\title{
Prevalence of Mycobacterium Tuberculosis and Dermatophytes Co-Infection in Human Immunodeficiency Virus (HIV) Patients
}

\author{
Abba Moses Audu ${ }^{1}$, Oche Joseph Otorkpa ${ }^{2}$, Odama Lillian Eniola ${ }^{1}$ \\ ${ }^{1}$ Department of Microbiology, KogiState University, Anyigba, Nigeria \\ ${ }^{2}$ Department of Public Health, Texila American University, Georgetown, Guyana
}

Email address:

drochejoseph@gmail.com (O. J. Otorkpa)

\section{To cite this article:}

Abba Moses Audu, Oche Joseph Otorkpa, Odama Lillian Eniola. Prevalence of Mycobacterium Tuberculosis and Dermatophytes CoInfection in Human Immunodeficiency Virus (HIV) Patients. Central African Journal of Public Health. Vol. 7, No. 4, 2021 , pp. $198-203$. doi: $10.11648 /$ j.cajph.20210704.18

Received: June 5, 2021; Accepted: July 12, 2021; Published: August 2, 2021

\begin{abstract}
The syndemic interaction between the Human Immuno Deficiency Virus (HIV) and opportunistic infections can have far reaching consequences on a person's health. HIV associated dermatophytic infections result in extensive skin lesions which can be difficult to treatdue to poor response to conventional antifungal therapy. HIV- associated tuberculosis especially also contributed substantially to the burden of tuberculosis-associated morbidity and mortality. The Aim of this research was to study the co-infection of mycobacterium tuberculosis and dermatophytosis in a HIV positive population visiting the HIV clinics in some hospitals around Anyigba, Kogi State, Nigeria. Skin scrap samples were collected from nine hundred and seventy six (976) HIV positive persons within six (6) months for analysis. Out of these, 56 patients had dermatophytes infection, the skin leisons and skin scrap samples were further analyzed to identify the dermatophytes. Descriptive analysis, Student $T$ tests and one way ANOVA were carried out to understand the various relationships. Most patient presented to the clinic with cough, fever, weight loss and multiple symptoms, and with CD4 values less than 200cells /ul and substantially between 200-349 cells/ $\mu 1$ and 350-499cells/ $\mu 1$. The Predominant age of patients with HIV co-infected with tuberculosis and dermatophytosis was between 25-34 years and 35-44 years respectively. Dermatophytes were mostly found in patients with CD4 values which were equal or lower than 200 cells/ $\mu 1$ irrespective of their age group. The predominant dermatophyte was Trichophyton species with Trichophyton tonsurans being the commonest species isolated followed by Trichophyton rubrum, Trichophyton mentagrophytes and Trichophyton gallinae. The finding of this study revealed that the prevalence of HIV infection led to higher progression rate of $10 \%$ active tuberculosis. It also revealed that Trichophyton species were the predominant dermatophytes in the environment with Trichophyton tonsurans being the most common isolate. Most patients visiting the hospital were already in the stage II and III of HIV infection in this area and the most common opportunistic infection is Tuberculosis.
\end{abstract}

Keywords: HIV Infection, Tuberculosis, Opportunistic Infections, Dermatophytes, Coinfection

\section{Introduction}

The Human Immunodeficiency Virus (HIV) was unknown until the early 1980 's, but it has since infected millions of persons across the globe, resulting in a worldwide pandemic. The prevalence of HIV in Nigeria is relatively low (1.5\%) but the large population means that over 1.8 million people are living with HIV as at 2019. [1] All HIV infected persons are at risk for illness and death from opportunistic infections and neoplastic complications as a result of the inevitable manifestations of AIDS. [2] The widespread use of AntiRetroviral Therapy (ART) starting in the mid-1990s has had the most profound influence on reducing opportunistic infections-related mortality in HIV-infected persons in places where these therapies are accessible and affordable $[3,4]$.

Studies have shown that owing to the weakened immune states, people living with HIV/AIDS are more vulnerable to infections. [5] These opportunistic infections may not be fatal in a person without HIV infection. However, they are the major causes of morbidity and death among patients with low CD4+ 
counts or who are in advanced stages of AIDS. Some of the opportunistic infections are those caused by bacteria (e.g. Mycobacterium tuberculosis, Bacteria pneumonia); Fungi (e.g. Candida albicans, Dermatophytes, Cryptococcosis, Pneumocystic, Jiroweci pneumonia or Pneumocystic carinni pneumonia PCP), Protozoan parasites (e.g. Toxoplasmosis, Cryptosporidiosis) and viruses (e.g. Herpes. Hepertitis). In view of the above, it is therefore imperative for the clinicians to identify and have a high index of suspicion of the common organisms implicated in HIV co-infection in their locality, especially in patients with low CD4counts as prompt diagnosis will lead to prompt institution of therapy, and invariably, a better outcome. This research therefore aims to identify these opportunistic pathogens in this group of patients in a locality in North Central Nigeria, to aid the clinician in resource poor settings like Africa make a more rational diagnosis as well as to add to the existing body of knowledge about HIV co-infections.

\section{Methodology}

\subsection{Study Design}

In order to obtain a representative sample, the HIV clinics of most utilized health facilities (Grimard Catholic Hospital, Anyigba, Christian Hospital, Ika and Holly Memorial Hospital, Ochadamu) were used for the study. Ethical approval was obtained from the managements of the selected hospitals. The calculated number of participants was rounded off to 976 . This number was then spread over the 3 hospitals in the ratio 3:2:1 (Grimard Catholic Hospital, Anyingba:Holly Memorial Hospital, Ochadamu:Christian Hospital, Ika), based on therecorded average patient population in the HIV clinic of these hospitals. The 976participants were chosen by simple random sampling over a six month period. Informed consent was then obtained from them. Blood, Sputum and Skin scrap samples were collected from the study subjects and sent to the microbiology laboratory of the Grimard Catholic Hospital. They were analyzed for the presence of dermatophytes and Tuberculosis to establish the presence or absence of these coinfections. The different dermatophytes species were identified after culture (see Appendices) and documented. The socio demographic characteristic of each participant was also recorded at recruitment.

\subsection{Data Analysis}

Descriptive analysis, student's t-test, Chi-square and one way ANOVA were carried out for the variables. P value was set at less than 0.05 for significance.

\section{Result}

The results show that $30.5 \%$ of the study subjects were within the age of range of $25-30$ years, $26.4 \%$ were within the age range of $31-36$ years, while $13.1 \%$ fell within the age range of 37-42 years.

The prevalence of HIV/ tuberculosis/ dermatophytes co- infection was studied for a period of 6 months; Nine hundred and seventy six (976) patients were recruited out of which 565 (57.9\%) patients had HIV/TB/Dermatophytosis. Four hundred and eighty three (483) (43.87\%) had HIV/TB co-infection, 56 (5.7\%) had HIV/dermatophytosis while $286(29.3 \%)$ participants had opportunistic infections other than TB/Dermatophytosis and 125 $(11.35 \%)$ subjects had only Tuberculosis.

The male to female ratio of patients with HIV co-infected with tuberculosis and dermatophtosis was $2: 3$ but statistical analysis showed no significant difference between the sex ratio in the study $(\mathrm{P}>0.05)$ while significant difference was observed between HIV/TB and HIV/Dermatophytes coinfection in the study.

Clinical manifestation in relation to CD4 values showed that $24.3 \%$ of the participants within the period of study had fever, $17.8 \%$ had chronic cough while $13.6 \%$ complained of weight loss. Those who presented with multiple complaints constituted $14.2 \%$. Out of the 976 study subjects, $34.9 \%$ presented with a CD4 count of less than 200 cells $/ \mu$, while $31.5 \%$ presented with CD4 counts between $200-349$ cells $/ \mu 1$.

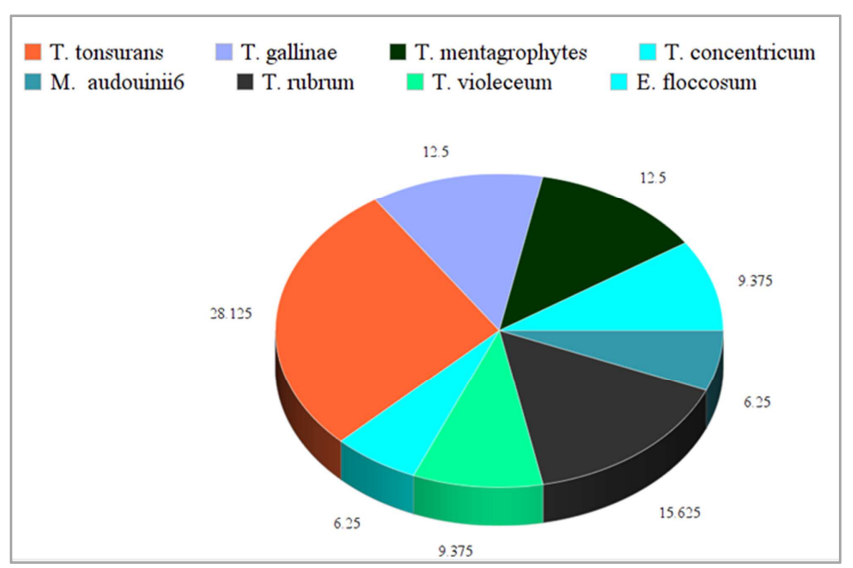

Figure 1. Pie chart showing the percentage of different species of dermatophytes co-infecting HIV patients.

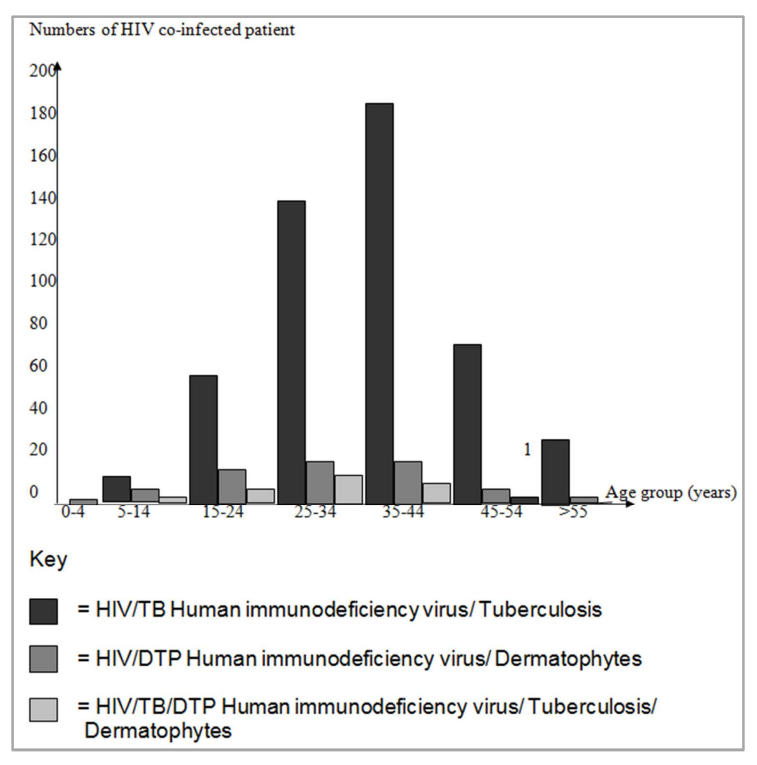

Figure 2. Bar chart showing the distribution of HIV co-infections. 
Regarding dermatophytes, the results showed that Trichophyton were abundant in this environment and essentially found in all anatomical sites were skin was scraped. T.tonsurans appeared most commonly than any species of dermatophytes isolated followed by T.rubrum, T. metagrophytes/ T.gallinae then T.concentricum/T.violeceum. However, E.floccosum was mainly gotten from perineum and M. audouini were found only in the head. In all, Trichophyton species were found in every part of the body with Microsporum in only the head and Epidermophyton in only the perineum.

The percentage of species of dermatophytes isolate and the prevalence of T.tonsurans was found to be high $(28.12 \%)$, followed by T.rubrum (15.62\%) T.metagrophytes (12.50\%), T.gallinae (12.50\%). Considerable numbers of T.concentricum and T.violeceum were found and the less common was F.floccosum and M.audonii.

\section{Discussion}

The male/female ratio of subjects affected with HIV and coinfected with Tuberculosis and skin lesion is ratio 2:3. This agrees with the findings of a study on Gender and Health inequalities published in 2017 which reported that the women were at higher risk of HIV infection because of their inability to negotiate condom use, or to reject forced sex and nonconsensual sex. [6] In addition, a similar study on gender and TB/HIV co-infection, presentation and treatment outcome in Nigeria reported a higher rate TB/HIV co-infection in females $(57.3 \%)$ as compared to men $(42.7 \%)$. [7]However these findings are in contrast with the outcome of a Brazilian study which reported that most HIV / Tuberculosis co-infection $(81 \%, p=0.0006)$ were found in men. [8] This variation could likely be due to social and environmental determinants of coinfection in HIV patients as reported by Oliveira and Gonçalvesin in their study conducted in 2013. [9]

Findings from this study also reveal that of the nine hundred and seventy six (976) participantsscreened, 565 representing $57.9 \%$ of patients had HIV/TB/Dermatophytosis in addition, 483 patients representing $43.87 \%$ of the study populationhad HIV/TB co-infection, This high prevalence agrees with the findings of a study on the prevalence of tuberculosis in HIV-seropositive patients which reported that the overall prevalence rate of TB in HIV to be $33.9 \%$. [10] Another study reported the prevalence of HIV/TB in the North Central State of Nassarawa to be $34.5 \%$. [11] These findings align with the report of the World Health Organization which stated that up to $70 \%$ of patients with sputum smear-positive pulmonary tuberculosis are HIVpositive in some countries in sub-Saharan Africa. [12]In contrast, a study conducted in Benue, North Central Nigeria reported a much lower HIV/TB co-infection rate of $19.8 \%$. This variation could be due to the studied population which was mostly children. [13]

South Africa and Nigeria rank among the worst affected by tuberculosis in Sub-Saharan Africa (SSA) and globally, despite comprising just $0.7 \%$ of the world's population, resulting in the largest burden in Africa. [14]In absolute terms, Nigeria remains among the world's highest TB burden countries, accounting annually for about $4 \%$ of the world's incident $\mathrm{TB}$ cases with an estimated incidence rate of 219/100,000 people. [15] However, result from this study showed an increase to 608/1101 from the previous burden of $311 / 100,000$ reported by USAID in 2010 implying an increase in tuberculosis burden due to HIV in Nigeria.

The result of the prevalence of dermatophytes in this study indicates that 56 subjects representing $5.7 \%$ of the study population had HIV/dermatophytosis. This finding is similar to the result obtained in a study on mucocutaneous manifestations in Human Immunodeficiency Virus (HIV)-infected patients published in the International Journal of Dermatology which reported the prevalence of dermatophyte infections in HIV patients to be $16.3 \%$. [16] This is however in contrast with another study on the subject matter which reported that $33.3 \%$ of patients with Human Immunodeficiency Virus infection haddermatophytosis. [17] The finding from this study did not also agree with the finding published in the Seminars in Dermatology which reported that up to $20 \%$ of HIV infected person developed dermatophytes typically stage 11 and 111 of HIV. [18] These disparities is likely due to environmental factors and stages presented in the hospital.

Results from this study indicatethatdermatophytes appeared more than other skin lesion in a ratio of 3:2 respectively. The Isolates of dermatophytes were 32 , out of which $\mathrm{T}$. tonsurans accounted for $28.12 \%$ followed by T.rubrum with $15.63 \%$. The dermatophytes isolated in this study were $\mathrm{T}$. tonsurans followed by T. rubrum and T. concentricum, E.flocosum, M. audouinii, T. gallinae, T. metagrophyte and T. violeceum. The predominant dermatophyte was Trichophyton species with Trichophyton tonsurans being the commonest species isolated followed by Trichophyton rubrum, Trichophyton mentagrophytes and Trichophyton gallinae. These finding agree with the results of a study on HIV patients published in 2019 which reported that among dermatophytes isolated, T. tonsurans was the commonest cause of infection. [19]In contrast, another study reported that Trichophyton rubrum (33.33\%), Trichophyton mentagrophytes $(33.33 \%)$, Candida albicans (16.67\%) and Aspergillus species (10.00\%) were the important species isolated from HIV patients with dermatophyte infections. [20]

Variation in the population of dermatophytes isolated fromHIV infected patients is not uncommon. [21] These differences have been reported to be related to conditions, such as host immune response against dermatophytes, and the infectedarea of the body where samples were taken. [22, 23]

Patients with HIV/TB and or dermatophytes were seen mostly at CD4+ counts of $<200$ cells $/ \mu 1$. This group constituted $34.94 \%$ of all the cases, this was closely followed by patientswithCD4 count range of between $200-349$ cells $/ \mu 1$ which accounted for $31.56 \%$ of cases. Patients with CD4 count rage of $350-499$ cells $/ \mu 1$ accounted for $25.72 \%$ of the cases, and the least was CD4 > 500 cells $/ \mu 1$. The above shows that patients with co-infections of HIV with TB and dermatophytes come to hospital with very low CD4 counts. 
Most patients with dermatophytes in HIV/TB co-infected patients visited the clinics with CD4 counts of $<200$ cells $/ \mu 1$ and $200-349$ cells $/ \mu 1$. This finding is similar to the results from other studies including a study published in the Asian Journal of Research In Infectious Diseases which reported that the highest rate of dermatophytosis in HIV seropositive group (41.65\%) were found among those with CD4 cell counts of less than200. [24, 25] In contrast, a study published in 2014, reported that CD4+ counts and CD4+/CD8+ ratios were not associated with a higher risk of dermatophytosis but viral load greater than 100000 copies/ml was associated with a higher frequency of dermatophytosis. [26] This variation could be due to dietary variation in the two study location asHIV negatively affects nutritional status, and poor nutrition further weakens the body's defence system, increasing susceptibility to opportunistic infections. Studies have shown that malnutrition was a significant predictor of opportunistic infections. Malnourished and undernourished HIV patients were associated with high risk and early development of opportunistic infections. [27]

\section{Conclusion}

The finding of this study revealed that the prevalence of HIV infection led to higher progression rate of active tuberculosis. It also revealed that Trichophyton species were the predominant dermatophytes in the environment with Trichophyton tonsurans being the most common isolate. Most patients visiting the hospital were already in the stage II and III of HIV infection in this area and the most common opportunistic infection is Tuberculosis.

\section{Further Research Needs}

This research has shown that HIV positive patients often present to the hospitals in stages 11 and 111 in the studied area, there may be need to study the attitudes of these people further to understand why this is so.

This research also has reported that trichochyton species is the most predominant dermatophyte isolated from HIV positive patients, there may also be need to repeat same study in other localities to know if this still holds in these places

There is also need to study other opportunistic infections in HIV like bacteria and other systemic fungal infections, to give a more holistic view of HIV co-infections

\section{Appendix}

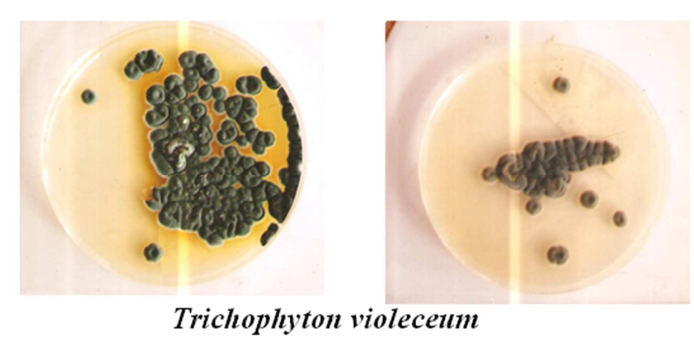

Figure 3. Petri dishes showing cultured Trichophytonvioleceum.

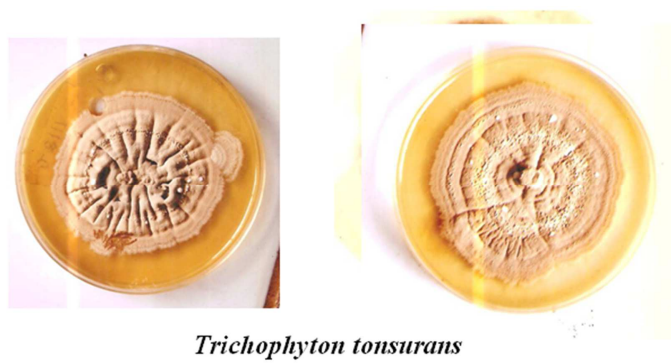

Figure 4. Petri dishes showing cultured Trichophytontonsurans.

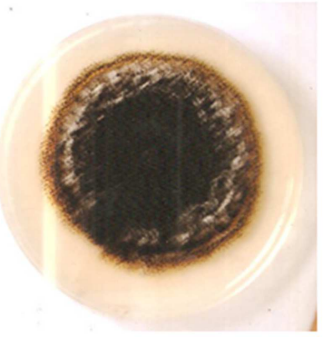

Microsportum audouinii

Figure 5. Petri dish showing cultured Microsporumaudouinii.

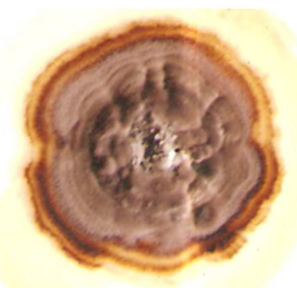

Trichophyton comcentricum

Figure 6. Petri dish showing cultured Trichophytonconcentricum.

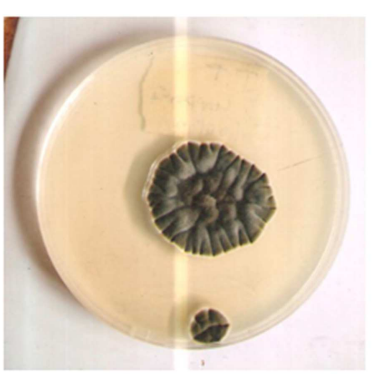

Trichophyton soudanese

Figure 7. Petri dish showing cultured Trichophyton Soudanese.

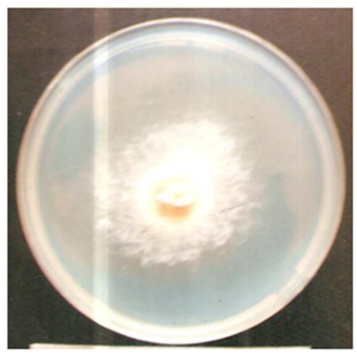

Trichophyton rubrum

Figure 8. Petri dish showing cultured Trichophytonrubrum. 


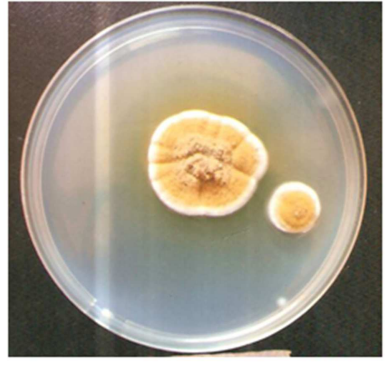

Epidemophyton floccosum

Figure 9. Petri dish showing cultured Trichophytonfloccosum.

\section{References}

[1] Ajayi, A. I., Awopegba, O. E., Adeagbo, O. A., \& Ushie, B. A. (2020). Low coverage of HIV testing among adolescents and young adults in Nigeria: Implication for achieving the UNAIDS first 95. PloS one, 15 (5), e0233368.

[2] Moss, A. R., \& Bacchetti, P. (1989). Natural history of HIV infection. Aids, 3 (2), 55-62.

[3] Detels, R., Munoz, A., McFarlane, G., Kingsley, L. A., Margolick, J. B., Giorgi, J.,...\& Multicenter AIDS Cohort Study Investigators. (1998). Effectiveness of potent antiretroviral therapy on time to AIDS and death in men with known HIV infection duration. Jama, 280 (17), 1497-1503.

[4] Dore, G. J., Li, Y., McDonald, A., Ree, H., \& Kaldor, J. M. (2002). Impact of highly active antiretroviral therapy on individual AIDS-defining illness incidence and survival in Australia. Journal of acquired immune deficiency syndromes (1999), 29 (4), 388-395.

[5] Miller, C. J., McGhee, J. R., \& Gardner, M. B. (1993). Biology of disease: mucosal immunity, HIV transmission, and AIDS. Laboratory investigation, 68 (2), 129-145.

[6] Vives-Cases, C., Eriksson, M., Goicolea, I., \& Öhman, A. (2015). Gender and health inequalities: intersections with other relevant axes of oppression. Global health action, 8 .

[7] Daniel, O. J., Oladapo, O. T., Salako, A. A., Iyaniwura, C. A., \& Oluwole, F. A. (2005). Gender and TB/HIV co-infection: presentation and treatment outcome in Nigeria. Nigerian Medical Practitioner, 47 (4), 58-60.

[8] Carvalho, Bráulio Matias de, André Jalles Monteiro, Roberto da Justa Pires Neto, Thalles Barbosa Grangeiro, and Cristiane Cunha Frota. "Factors related to HIV/tuberculosis coinfection in a Brazilian reference hospital." Brazilian Journal of Infectious Diseases 12, no. 4 (2008): 281-286.

[9] Oliveira, N. F. D., \& Gonçalves, M. J. F. (2013). Social and environmental factors associated with the hospitalization of tuberculosis patients. Revista latino-americana de enfermagem, $21(2), 507-514$.

[10] Affusim, C. C., Kesieme, E., \& Abah, V. O. (2012). The pattern of presentation and prevalence of tuberculosis in HIVseropositive patients seen at Benin City, Nigeria. International Scholarly Research Notices, 2012.

[11] Gyar, S. D., Dauda, E., \& Reuben, C. R. (2014). Prevalence of tuberculosis in HIV/AIDS patients in Lafia, Central Nigeria. Int. J. Curr. Microbiol. App. Sci, 3 (6), 831-838.
[12] WHO. (2020, April 30). Joint HIV/Tuberculosis Interventions. Https://Www.Who.Int/Hiv/Topics/Tb/Tuberculosis/En/.

[13] Anígilájé, E. A., Aderibigbe, S. A., Adeoti, A. O., \& Nweke, N. O. (2016). Tuberculosis, before and after antiretroviral therapy among HIV-infected children in Nigeria: what are the risk factors?. PLoS One, 11 (5), e0156177.

[14] Nachega, J. B., Kapata, N., Sam-Agudu, N. A., Decloedt, E. H., Katoto, P. D., Nagu, T.,... \& Zumla, A. (2021). Minimizing the impact of the triple burden of COVID-19, tuberculosis and HIV on health services in sub-Saharan Africa. International Journal of Infectious Diseases.

[15] Abdullahi, S. A., Smelyanskaya, M., John, S., Adamu, H. I., Ubochioma, E., Kennedy, I.,...\& Creswell, J. (2020). Providing TB and HIV outreach services to internally displaced populations in Northeast Nigeria: Results of a controlled intervention study. PLoS medicine, 17 (9), e1003218.

[16] Boushab, B. M., Malick Fall, F. Z., Ould Cheikh Mohamed Vadel, T. K., Ould Cheikh Melaïnine, M. L., Maazouz, M. V., Savadogo, M., \& Basco, L. K. (2017). Mucocutaneous manifestations in human immunodeficiency virus (HIV)infected patients in Nouakchott, Mauritania. International journal of dermatology, 56 (12), 1421-1424.

[17] Costa, J. E. F., Neves, R. P., Delgado, M. M., Lima-Neto, R. G., Morais, V. M. S., \& Coêlho, M. R. C. D. (2015). Dermatophytosis in patients with human immunodeficiency virus infection: Clinical aspects and etiologic agents. Acta tropica, 150, 111-115.

[18] Berger, T. G. "Treatment of bacterial, fungal, and parasitic infections in the HIV-infected host." In Seminars in dermatology, vol. 12, no. 4, pp. 296-300. 1993.

[19] Narang, Kirti, Manish Pahwa, and V. Ramesh. "Tinea capitis in the form of concentric rings in an HIV positive adult on antiretroviral treatment." Indian journal of dermatology 57.4 (2012): 288.

[20] Vinnakoti, A., Boina, K., \& Purushothaman, S. Clinicomycological profile of onychomycosis in HIV patients at a tertiary care centre, Kakinada.

[21] Araya, S., Tesfaye, B., \& Fente, D. (2020). Epidemiology of dermatophyte and non-dermatophyte fungi infection in Ethiopia. Clinical, cosmetic and investigational dermatology, $13,291$.

[22] AL-Khikani, F. H., \& Ayit, A. S. (2021). Major challenges in dermatophytosis treatment: current options and future visions. Egyptian Journal of Dermatology and Venerology, 41 (1), 1.

[23] Heinen, M. P., Cambier, L., Fievez, L., \& Mignon, B. (2017). Are Th17 cells playing a role in immunity to dermatophytosis?. Mycopathologia, 182 (1-2), 251-261.

[24] UTHAYAKUMAR, S., Nandwani, R., Drinkwater, T., Nayagam, A. T., \& Darley, C. R. (1997). The prevalence of skin disease in HIV infection and its relationship to the degree of immunosuppression. British Journal of Dermatology, 137 (4), 595-598.

[25] Altraide, D. D., Amaewhule, M. N., \& Otike-Odibi, B. (2021). Prevalence, Pattern and Clinical Variations of Dermatophytosis in Patients with HIV Infection at the University of Port Harcourt Teaching Hospital, Port Harcourt. Asian Journal of Research in Infectious Diseases, 33-43. 
[26] Da Silva, B. C. M., Paula, C. R., Auler, M. E., Ruiz, L. D. S., Dos Santos, J. I., Yoshioka, M. C. N.,... \& Gambale, W. (2014). Dermatophytosis and immunovirological status of HIVinfected and AIDS patients from Sao Paulo city, Brazil. Mycoses, 57 (6), 371-376.
[27] Hussen, S., Belachew, T., \& Hussein, N. (2017). Nutritional status of HIV clients receiving HAART: its implication on occurrence of opportunistic infection. The Open Public Health Journal, 10 (1). 